\title{
Analyzing Systemic Risk in the Chinese Banking System
}

Abstract. We examine systemic risk in the Chinese banking system by estimating the conditional value at risk (CoVaR), the marginal expected shortfall (MES), the systemic impact index (SII) and the vulnerability index (VI) for 16 listed banks in China for the 2007-2014 period. We find that these measures show different patterns, capturing different aspects of systemic risk of Chinese banks. However, rankings of banks based on these measures are significantly correlated. The time series results for the CoVaR and MES measures suggest that systemic risk in the Chinese banking system decreased after the global financial crisis but started rising in 2014.

Keywords: systemic risk, Chinese banks, CoVaR, marginal expected shortfall JEL Classification: G21, G28, G14.

\section{Introduction}

Macro-prudential regulation, which aims to reduce systemic risk and achieve financial stability, has been one of the most important policy innovations after the global financial crisis (Kim and Chey, 2010; Blinder et al., 2016). However, to implement such regulation, policymakers need to identify systemic risk in the banking system. This paper analyzes systemic risk in the Chinese banking system. China has achieved remarkable progress in reforming its banking system. Currently, there are 117 Chinese banks in the 2015 Top 1000 World Banks ranking; ${ }^{1}$ three of them (the Bank of China, the Industrial and Commercial Bank of China, and the Agricultural Bank of China) $)^{2}$ are rated as global systemically important banks. Chinese banks made $\$ 292$ billion in aggregate pretax profit in 2013 , or $32 \%$ of total earnings of the world's top 1,000 banks,

\footnotetext{
${ }^{1}$ See report published on 29 June, 2015 in The Banker, available at http://www.thebanker.com/Top-1000World-Banks/Top-1000-World-Banks-China-s-banks-show-no-signs-of-slowdown.

${ }^{2}$ See the 2014 update of the list of global systemically important banks (G-SIBs), 6 November 2014, available at http://www.financialstabilityboard.org/2014/11/2014-update-of-list-of-global-systemically-important-banks/.
} 
outperforming US banks (with a share of $20 \%$ ), according to The Banker magazine. ${ }^{3}$ However, the Chinese banking system faces numerous challenges. Economic growth in China has been slowing down since the global financial crisis and its export-led growth path does not seem sustainable (Aizenman, 2015), overcapacity in some sectors is becoming increasingly serious, and there seems to be a bubble in the real estate market, whose financing mainly depends on banking loans. No doubt, these challenges may affect the stability of the banking system. ${ }^{4}$ Furthermore, the rapid expansion of China's shadow-banking sector may pose a threat to banking stability ( $\mathrm{Li}$, 2014), as illustrated by the default (or near-default) of several trusts exposed to the coalmining sector in 2014. ${ }^{5}$ Banks are not immune to the risks of the shadow-banking sector, as many of them distribute wealth management products or refinance trust companies.

A banking crisis in China would create enormous problems not only in China but also in other countries (see Feldkircher and Korhonen (2014) and Qiu and Zhan (2016) for evidence on China's increasing influence on the global economy). It therefore seems wise to nip the risk in the bud. And for this we need to analyze systemic risk objectively and accurately. According to official reports, the ratio of non-performing loans is about $1 \%$ for the vast majority of banks, indicating a good health of the banking system. However, China's official figures are often of questionable reliability, as argued by Krugman (2011). Therefore, our research resorts to market data, providing a more objective analysis of the soundness of the Chinese banking system.

We investigate systemic risk via several measures. More specifically, we apply the conditional value at risk (CoVaR) measure of Adrian and Brunnermeier (2016), the marginal expected shortfall (MES) measure of Acharya et al. (2010), the systemic impact index (SII) and the vulnerability index (VI) of Zhou (2010) to 16 listed banks in China for the 2007-2014 period. ${ }^{6}$ The former two are widely used to monitor financial institutions by central bankers and bank regulators and have a high impact in academia (Benoit et al., 2013). The latter two are based on a

\footnotetext{
${ }^{3}$ See http://www.reuters.com/article/2014/06/29/us-banks-rankings-china-idUSKBNOF411520140629.

${ }^{4}$ As Fenech et al. (2014) point out, loan quality of the Chinese banking system is directly linked to real estate and government supported infrastructure projects. Koetter and Poghosyan (2010) also find that house price fluctuations contribute to bank instability. Pasiouras and Kosmidou (2007) and Athanasoglou et al. (2008) find that macroeconomic conditions have a significant effect on banks' performance.

${ }^{5}$ See www.thebanker.com/Top-1000-World-Banks/Top-1000-World-Banks-2014-Back-on-track.

${ }^{6}$ We also consider the SRISK approach of Brownlees and Engle (2012) but we find that this approach may not applicable to Chinese banks because the results are zero for all banks considered in the 2007-2010 period, which seems counter intuitive. We provide details of the SRISK measure in an online Appendix.
} 
different estimation method (namely, Extreme Value Theory). These measures, calculated using daily equity returns, are used to capture each bank's contribution to systemic risk.

We find that the four measures of systemic risk diverge, as they capture different aspects of systemic risk in the banking system. However, the rankings of banks based on these measures are significantly correlated. Moreover, the time series results for the CoVaR and MES measures suggest that systemic risk in the Chinese banking system decreased after the global financial crisis but started rising in 2014. We also compare our findings for Chinese banks with similar results for Korean banks, and find that Chinese banks have higher $\triangle \mathrm{CoVaR}$ and lower MES than Korean banks, suggesting that the Chinese banking system is systemically riskier but individual banks seem to be more capable of avoiding losses from distress in the banking system.

Our paper contributes to the academic literature on the Chinese banking system. In the past decade, several papers have been published, analyzing different aspects of the Chinese banking system. To name a few, Hasan et al. (2015) investigate the Chinese banking structures and their effect on small business development; Garcia-Herrero et al. (2006), Fu and Heffernan (2009), Lin and Zhang (2009), and Dong et al. (2016) focus on the reform and performance of the Chinese

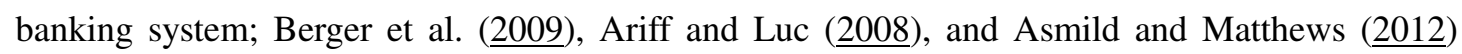
investigate the efficiency of Chinese banks; while Bailey et al. (2012) and Fenech et al. (2014) investigate the quality of bank loans and some other characteristic of the Chinese banking system. However, only a few studies investigate systemic risk in the Chinese banking system. Chen et al. (2014) apply an indicator-based approach proposed by the Basel Committee to identify domestic systemically important banks (D-SIBs) and analyze their correlation with non-D-SIBs. Wang et al. (2015) employ a Merton model to estimate the default probability of banks to construct a systemic risk index of banks. Gang and Qian (2015) examine the impact of China's monetary policy on systemic risk, using CoVaR. To the best of our knowledge, this is the first study that constructs multiple measures of systemic risk for Chinese banks. We also compare systemic risk of Chinese banks to that of banks in Korea.

The rest of this paper is organized as follows. Section 2 reviews the Chinese banking system. Section 3 introduces the systemic risk measures and describes the data. Section 4 provides the results. Section 5 concludes and discusses. 


\section{A brief review of the Chinese banking system}

In the 1990s, the banking system in China was dominated by four large state-owned banks. In addition, there were 13 joint-stock banks and 18 city commercial banks. However, the four state-owned big banks faced serious problems, such as high non-performing loans and inefficient operation and management. The Chinese authorities learned their lessons from the Asian financial crisis, initiating a series of reforms on the banking system in 2003; the first step was the restructuring of the state-owned commercial banks.

The successful reform of the Bank of China (BOC) and the China Construction Bank (CCB), two of the four state-owned banks, which consisted of disposing of non-performing assets, establishing modern corporate governance frameworks and introducing strategic investors, was followed by reform of the other two state-owned banks, the Industrial and Commercial Bank of China (ICBC) and the Agricultural Bank of China (ABC). The four state-owned banks became joint-stock commercial banks and they have been listed on the Shanghai Stock Exchange since 2006. Reforms were also implemented in other small and medium-sized commercial banks and rural credit cooperatives since $2003 .^{7}$

After the reform, the Chinese banking system became more and more comprehensive and diversified, playing a dominated role in the Chinese financial system. At the end of 2013, it comprised of three development banks, five large-scale commercial banks, 12 joint-stock commercial banks, 145 city commercial banks, 468 rural commercial banks, 122 rural cooperative banks, 1803 rural credit cooperatives, 1134 new rural financial institutions, one postal savings bank, and 92 branches of foreign banks or non-bank financial institutions, according to the classification and statistics of the China Banking Regulatory Commission (CBRC) and the People's Bank of China (PBC). ${ }^{8}$ According to the Chinese Financial Stability Reports (2009-2014), the banking system accounted for more than 90\% of total asset of all financial intermediation since 2008. Besides, total assets, liabilities and profits of the Chinese banking

\footnotetext{
${ }^{7}$ For further details of the reform process of Chinese banks we refer to García Herrero et al. (2004), García Herrero et al. (2006), Podpiera (2006), Fu and Heffernan (2009), and Lin and Zhang (2009).

${ }^{8}$ Data sources: "The Agenda of Regulatory Statistical Information in 2014, Scope of Institutions and Indi cator's Explanation", http://www.cbrc.gov.cn/chinese/home/docView/DF50505B98DF45E1916AEC2BBCD55E1 E.html; "China Banking Regulatory Commission Annual Report 2013”, http://www.cbrc.gov.cn/chinese/hom e/docView/3C28C92AC84242D188E2064D9098CFD2.html; and "China Financial Stability Report 2014", htt p://www.pbc.gov.cn/publish/jinrongwendingju/369/index.html.
} 
system grew rapidly since 2003. Total assets and total liabilities grew from 28 trillion Yuan and 27 trillion Yuan in 2003 to 151 trillion Yuan and 141 trillion Yuan in 2013 with an average growth rate of $18 \%$ (see Figure 1). Profits before taxes of the banking system grew from 32 million Yuan in 2003 to 338 million Yuan in 2006 with an average growth rate of 119\%, while the profit after tax of the banking system grew from 447 million Yuan in 2007 to 1744 million Yuan in 2013, with an average growth rate of $25 \%$ (see Figure 2).

[Insert Figures $\underline{1}$ and $\underline{2}$ here]

Although the Chinese banking system was becoming diversified, it was still dominated by several big banks. For example, five large-scale commercial banks accounted for $43 \%$ of total assets of the Chinese banking system at the end of 2013 and 12 joint-stock commercial banks for 18\% (see Figure 3). The after-tax profits of the Chinese banking system had a similar distribution as banking assets. In 2013, the five large-scale commercial banks accounted for $48 \%$ of total after-tax profits and the 12 joint-stock commercial banks for 17\% (see Figure 4).

[Insert Figures $\underline{3}$ and $\underline{4}$ here]

\section{Methodology and data}

Several measures of systemic risk have been developed since the global financial crisis (Bisias et al. (2012) provide a detailed overview of 31 quantitative measures of systemic risk). These measures mainly rely on market data, as they are believed to effectively reflect information about publicly traded firms. ${ }^{9}$ Lo (2008) and Bisias et al. (2012) suggest to analyze systemic risk based on multiple measures rather than on a single measure, because the banking system is complex and dynamic, while no single measure is able to capture all aspects of systemic risk. Following this suggestion, in this paper the conditional value at risk (CoVaR) measure, the marginal expected

\footnotetext{
${ }^{9}$ We focus on measures relying on stock returns because the CDS market in China is still under development and there is not enough data for our purposes. In September 2016, the Chinese government approved trading of CDS by financial institutions in the nation's interbank market (See http://www.bloomberg.com/news/articles/201609-22/china-said-to-allow-trading-of-cds-in-nation-s-interbank-market-ite5sevi). As for the Chinese stock market, it has become fairly efficient after the reform in 2005-2006 (see Wang et al., 2010; Patel et al., 2012; Chong et al., 2012).
} 
shortfall (MES), the systemic impact index (SII) and the vulnerability index (VI) are applied to the Chinese banking system.

We choose these four measures of systemic risk because they have been widely used in recent years, both in academia and regulatory institutions. Besides, they capture systemic risk from different angles. CoVaR and SII aim to detect the spillover effects from a bank's distress to the banking system whereas MES and VI are designed to evaluate a bank's fragility by calculating the expected loss or the probability of distress of the bank when the banking system is confronted with distress. CoVaR and SII appear as the appropriate measures for systemic risk triggered by a single bank, according to their definition. MES and VI reverse the conditioning and shift the focus to a particular bank's fragility conditional on market distress. Acharya et al. (2010) and Brownlees and Engle (2012) argue that only when the market is in distress, individual banks' distress can have severe consequences for the financial system. Therefore, MES and VI can also serve as systemic risk measures.

\subsection{CoVaR: definition and estimation}

CoVaR, short for value at risk of the financial system conditional on institutions being under distress, has been proposed by Adrian and Brunnermeier (2016), henceforth AB. They define an institution's contribution to systemic risk as the difference between the CoVaR conditional on the institution being under distress and the CoVaR conditional on the institution being in normal state. Note that the value at risk of institution $i\left(V a R_{q}^{i}\right)$ can be defined as:

$$
\mathrm{P}\left(r^{i} \leq \operatorname{VaR}_{q}^{i}\right)=q
$$

where $r^{i}$ is the return of institution $i$ and $V a R_{q}^{i}$ is the Value-at-Risk of institution $i$ at quantile $q$ in a given time horizon. As a result, the $\operatorname{CoVaR}_{q}^{s \mid i}$ can be expressed as the $q$-quantile of the conditional probability distribution:

$$
\mathrm{P}\left(r_{t}^{s} \leq \operatorname{CoVaR}_{q}^{s \mid i} \mid r_{t}^{i}=\operatorname{VaR}_{q, t}^{i}\right)=q
$$

where $\operatorname{CoVaR} R_{q, t}^{s \mid i}$ is denoted by the VaR of system $s$ conditional on the institution $i$ being in its VaR. Thus, the contribution of institution $i$ to the risk of system $s$ is denoted by 


$$
\Delta \operatorname{CoVaR}_{q}^{s \mid i}=\operatorname{CoVaR}_{q}^{s \mid r^{i}=\operatorname{VaR}_{q}^{i}}-\operatorname{CoVaR}_{q}^{s \mid r^{i}=\operatorname{Median}^{i}}
$$

where $\Delta \operatorname{CoVaR}_{q}^{s \mid i}$ is the contribution of institution $i$ to the systemic risk of the system. AB use the median return of institution $i$ as a proxy of a normal state of institution $i$.

Girardi and Tolga Ergun (2013) modify AB's CoVaR through assuming that the conditioning financial distress event refers to the return of institution $i$ being at most at its $\operatorname{VaR}\left(R^{i} \leq V a R^{i}\right)$ as opposed to being exactly at its $\operatorname{VaR}\left(R^{i}=V a R^{i}\right)$. Thus, Equation 2 is replaced by:

$$
\mathrm{P}\left(r^{s} \leq \operatorname{CoVaR}_{q}^{s \mid i} \mid r_{t}^{i} \leq \operatorname{VaR}_{q, t}^{i}\right)=q
$$

This specification has three advantages over AB's CoVaR. First, it allows us to consider more severe distress events of institution $i$ that are further away in the tail (beyond its VaR). In addition, it improves the consistency of CoVaR with respect to the conditional dependence of the system on individual institutions (Mainik and Schaanning, 2014). Lastly, due to the time-varying correlation between an institution and the system in Girardi and Tolga Ergun's (2013) CoVaR, it allows the linkage to be changing over time while this is assumed to be constant in $\mathrm{AB}$.

Therefore, we adopt the version of Girardi and Tolga Ergun (2013) and calculate the CoVaR metric following their three-step procedure. Firstly, we calculate VaR of each bank $i$ based on a GARCH(1,1) model and secondly, using the DCC $(1,1)$ model we estimate the bivariate density of each bank and the system. ${ }^{10}$ After these two steps, we can calculate CoVaR at the distressed state $(\mathrm{q}=0.05)^{11}$ and at the benchmark state $\left(\mu_{t}^{i}-\sigma_{t}^{i} \leq r_{t}^{i} \leq \mu_{t}^{i}+\sigma_{t}^{i}\right)$ from the dual integral equations (5) and (6):

$$
\int_{-\infty}^{\operatorname{CoVaR} R_{q, t}^{s \mid i}} \int_{-\infty}^{\operatorname{VaR}} \mathrm{R}_{q, t}^{i} p d f_{t}(x, y) d y d x=q^{2}
$$

\footnotetext{
${ }^{10}$ We choose the GARCH $(1,1)$ and $\operatorname{DCC}(1,1)$ specifications following Engle's suggestion that these best fit most financial time series. The dynamic conditional correlation (DCC) model has been introduced by Engle (2002). We adopt this model to obtain the time-varying correlation between returns of the system and the institution. Notice that we estimate their correlation rather than their causal relationship, and the DCC model has taken into account the variables' autocorrelation. Thus, $\Delta \mathrm{CoVaR}$ is just a tail-dependency measure and does not necessarily reflect causality (Adrian and Brunnermeier, 2016). This argument also holds for the MES measure as discussed in Section 3.2 .

${ }^{11}$ In practice, the quantiles of 0.05 and 0.01 are widely used to weigh the extreme risk of a bank. We adopt the quantile of 0.05 for two reasons: 1) since banking crises have not occurred in China, there are too few observations in the tail distributions of banks' return at quantile 0.01 ; 2) papers used to compare our findings for the Chinese banking system with those of other countries also use the 0.05 quantile.
} 


$$
\int_{-\infty}^{\operatorname{CoVaR} R_{q, t}^{s \mid i}} \int_{\mu_{t}^{i}-\sigma_{t}^{i}}^{\mu_{t}^{i}+\sigma_{t}^{i}} p d f_{t}(x, y) d y d x=p_{t}^{i} q
$$

where $p d f_{t}(x, y)$ is the joint probability density function of $x$ and $y$ at time $t$, and $p_{t}^{i}=P\left(\mu_{t}^{i}-\right.$ $\left.\sigma_{t}^{i} \leq r_{t}^{i} \leq \mu_{t}^{i}+\sigma_{t}^{i}\right)$

Finally, $\triangle \mathrm{CoVaR}$ is the percentage difference between the CoVaR at the distressed state and at the benchmark state, as defined in Equation (7):

$$
\Delta \operatorname{CoVaR} R_{q, t}^{s \mid i}=100 \times\left(\operatorname{CoVaR}_{q, t}^{s \mid i}-\operatorname{CoVaR}_{q, t}^{s \mid b^{i}}\right) / \operatorname{CoVaR}_{q, t}^{s \mid b^{i}}
$$

Thus, $\Delta \mathrm{CoVaR}$ reflects the spillover effect from a bank to the system, indicating the percentage change of VaR of the system when the bank being in distress and in normal state.

\subsection{MES: definition and estimation}

Acharya et al. (2010) consider a financial institution's contribution to systemic risk as its expected loss when the market declines substantially. Under the definition of VaR in Eq. (1), the expected shortfall (ES), which is the expected loss conditional on something bad happening, can be defined as follows:

$$
E S_{\alpha}=E\left[R \mid R \leq V a R_{\alpha}\right]
$$

In order to get a bank's marginal expected shortfall (MES), define $R$ as the total return of the banking system and decompose it into the sum of each bank's return $\left(r_{i}\right)$, that is $R=\sum_{i} y_{i} r_{i}$, where $y_{i}$ is the weight of bank $i$ in the banking system. Then we have:

$$
E S_{\alpha}=\sum_{i} y_{i} E\left[r_{i} \mid R \leq V a R_{\alpha}\right]
$$

and

$$
M E S_{\alpha}^{i}=\frac{\partial E S_{\alpha}}{\partial y_{i}}=\mathrm{E}\left[r_{i} \mid R \leq V a R_{\alpha}\right]
$$

Thus, $M E S_{\alpha}^{i}$ measures bank $i$ 's average equity return on days when the return of the entire banking system drops below a threshold (i.e. $V a R_{\alpha}$ ).

In Acharya et al. (2010), a bank's MES is the average return of its equity $\left(R_{b}\right)$ during the $5 \%$ 
worst days for the overall market return $\left(R_{m}\right)$, where the market is presented by the CRSP Value Weighted Index or the financial subsector's index:

$$
M E S_{i}=\frac{1}{\text { number of the } 5 \% \text { worst days }} \sum_{\{t: s y s t e m \text { is in its } 5 \% \text { tail }\}} R_{i, t} .
$$

This method is simple but it may not get sound results when there are few extreme events in the tail of the return distribution. Furthermore, Acharya et al. (2010) assume the probability of observing a conditioning event to be constant, which is somewhat far from reality as it is more probable to observe losses beyond a given threshold when the volatility is higher. Brownlees and Engle (2012) propose an alternative method to calculate MES which might overcome these shortcomings. Therefore, we adopt Brownlees and Engle's method to calculate MES via the following three steps: 1) Modeling volatilities by GARCH models to obtain conditional volatility and standardized residuals; 2) Resorting to a DCC specification to obtain conditional correlation and the standardized idiosyncratic firm residual; 3) Inference on the model innovations is based on the GARCH/DCC residuals. The one period ahead MES can be expressed as:

$M E S_{t-1}^{i \mid s}=\sigma_{i, t} \rho_{i s, t} E_{t-1}\left(\epsilon_{s, t} \mid \epsilon_{s, t} \leq V a R_{s, t} / \sigma_{s, t}\right)+\sigma_{i, t} \sqrt{1-\rho_{i s, t}^{2}} E_{t-1}\left(\varepsilon_{i, t} \mid \epsilon_{s, t} \leq V a R_{s, t} / \sigma_{s, t}\right)$,

where, $\mathrm{E}()$ is the tail expectation of the standardized innovations distribution, $\rho_{i s}$ is the dynamic conditional correlation between bank $i$ and system $s, \sigma_{i}$ and $\sigma_{s}$ are time-varying conditional standard deviations. We only need to estimate the tail expectations of the standardized innovations distribution because the dynamic conditional correlation and conditional standard deviations have been calculated from the GARCH/DCC model in the previous sub-section. Following Brownlees and Engle (2012), we resort to a nonparametric kernel estimation approach to compute the tail expectations. Let

$$
K_{h}(\mathrm{t})=\int_{-\infty}^{t / h} k(u) d u
$$

where $k(u)$ is a kernel function and $h$ is a positive bandwidth. Then

$$
\widehat{E}_{h}\left(\epsilon_{s, t} \mid \epsilon_{s, t} \leq k\right)=\frac{\sum_{i=1}^{n} \epsilon_{s, t} K_{h}\left(\epsilon_{s, t}-k\right)}{n \hat{p}_{h}}
$$


and

$$
\widehat{E}_{h}\left(\varepsilon_{i, t} \mid \epsilon_{s, t} \leq k\right)=\frac{\sum_{i=1}^{n} \varepsilon_{S, t} K_{h}\left(\epsilon_{s, t}-k\right)}{n \hat{p}_{h}}
$$

where $\hat{p}_{h}=\frac{\sum_{i=1}^{n} K_{h}\left(\epsilon_{s, t}-k\right)}{n}$. Thus, MES reflects the vulnerability of individual banks, indicating the expected loss of individual banks conditional on the system being in distress.

\subsection{SII and VI: definition and estimation}

We introduce the SII and the VI measures together in this section because they have some common backgrounds and estimation methods. The SII and VI measures have been developed by Zhou (2010) through extending the concept of the "probability that at least one bank becomes distressed" (PAO) in Segoviano and Goodhart (2009). According to Zhou (2010), SII measures the expected number of bank failures in the banking system given that one particular bank fails, whereas VI measures the probability that a particular bank fails when there is at least one other failure in the system. Thus, SII and VI are defined by Equation (16) and Equation (17), respectively:

$$
\operatorname{SII}_{i}(p)=E\left(\sum_{j=1}^{d} 1_{X_{j}>\operatorname{VaR}_{j}(p)} \mid X_{i}>\operatorname{VaR}_{i}(p)\right)
$$

where $1_{A}$ is the indicator function that is equal to 1 when A holds, and is 0 otherwise; and

$$
\operatorname{VI}_{i}(p)=P\left(X_{i}>\operatorname{VaR}_{i}(p) \mid\left\{\exists j \neq i \text {, s.t. } X_{j}>\operatorname{VaR}_{j}(p)\right\}\right) .
$$

Zhou (2010) uses extreme value theory (EVT) to compute the SII and the VI. Suppose $\left(X_{1}, X_{2}, \cdots, X_{d}\right)$ follows the multivariate EVT setup, then we have

$$
S I I_{i}=\lim _{p \rightarrow 0} S I_{i}(p)=\sum_{j=1}^{d}\left(2-L_{i, j}(1,1)\right)
$$

and

$$
V I_{i}=\lim _{p \rightarrow 0} V I_{i}(p)=\frac{L_{i \neq 1}(1,1, \cdots, 1)+1-L(1,1, \cdots, 1)}{L_{i \neq 1}(1,1, \cdots, 1)}
$$

where $L(1,1, \cdots, 1)$ is the $\mathrm{L}$ function characterizing the tail dependence of $\left(X_{1}, X_{2}, \cdots, X_{d}\right)$, and 
$L_{\neq i}(1,1, \cdots, 1)$ is the $\mathrm{L}$ function capturing the tail dependence of $\left(X_{1}, \cdots, X_{i-1}, X_{i+1}, \cdots X_{d}\right)$. More details about the L function and the derivation of equations (18) and (19) are provided in de Haan and Ferreira (2007) and Zhou (2010). Before obtaining the results of SII and VI, we need to estimate the L function. According to Zhou (2010), a counting measure ${ }^{12}$ is applied to estimate the $L(1,1, \cdots, 1)$, then we have

$$
\widehat{L}(1,1, \cdots, 1)=\frac{1}{k} \sum_{s=1}^{n} 1_{\exists 1 \leq i \leq d}, \text { s.t. } X_{i s}>X_{i, n-k} .
$$

In equation (20), a critical issue is the choice of the value of $k$. Zhou (2010) suggests to calculate the estimator of $L(1,1, \ldots 1)$ under different $k$ values and draw a line plot against the $k$ values, then picking the first stable part of the line plot starting from low $k$, which balances the trade-off between the variance arising from low $k$ values and the bias arising from high $k$ values. Following this procedure, we finally choose $k=60$, which corresponds to a $p$ of $3.4 \%$. Thus, SII reflects the spillover effect from a bank to other banks, indicating the expected number of distressed banks when a particular bank becomes distressed. The VI mirrors a bank's capacity to cope with shocks from other banks' failures by calculating the probability of failure of a particular bank.

\subsection{Sample and data summary}

We investigate systemic risk of Chinese banks employing the different measures introduced above using time series data of 14 commercial banks' equity price during September 25, 2007December 31,2014 . We focus on 14 banks because there are only 16 banks listed in China's stock exchange and two of them are listed only since 2010 (the Agricultural Bank of China and the China Everbright Bank). The chosen period depends on data availability and our goal to use a long time period in order to observe the dynamics of banks' systemic risk before and after the global financial crisis. We also compute systemic risk of the other two banks during September 1, 2010 to December 31, 2014. Although there are only 16 (14) banks investigated, they capture a substantial part of the banking system in China in view of their dominant position. The 16 banks include five large-scale commercial banks, eight national joint-stock commercial banks and three city joint-stock commercial banks according to the classification of the China Banking Regulatory

\footnotetext{
${ }^{12}$ For more details about the counting measure, see van Oordt and Zhou (2012).
} 
Commission. Their combined assets account for more than $79 \%$ of all commercial banks.

Data for equity prices of banks is obtained from $\mathrm{TDX}^{13}$, as are data of the banking sector index (BSI). The summary statistics for the banks and the BSI are listed in Table 1. As Table 1 shows, average equity returns of all banks nearly equal 0 , which indicates that our assumption of zero mean return is valid for the data set employed. We also observe that all daily returns exhibit high kurtosis and skewness compared with the kurtosis and skewness from the normal distribution, which are 3 and 0.

[Insert Table 1 here]

\section{Results and analysis}

This section first presents the results for the four measures of systemic risk. Then we compare the rankings of banks under these four measures. Furthermore, we link our findings for Chinese banks to systemic bank risk estimations for Korea to get a better understanding of the degree of systemic risk in the Chinese banking system.

\subsection{Results for $\triangle$ CoVaR}

Table 2 shows the dynamic conditional correlation (DCC) between each bank and the banking system, the value at risk $(\mathrm{VaR})$ at the $5 \%$ quantile of each bank and the $\Delta \mathrm{CoVaR}$ of each bank during the whole sample period. The average DCC of all banks is above 0.8 (see Column 7 in Table 2), indicating strong links between each bank and the banking system, which implies that distress in one bank will easily propagate to other banks. Corresponding to the strong links, we find that the $\Delta \mathrm{CoVaR}$ is associated with the DCC while the VaR (5\%) is not. The cross-section correlation coefficient between banks' average $\triangle \mathrm{CoVaR}$ and their average $\mathrm{DCC}$ is as high as 0.99 , while it is negative (-0.11) for banks' VaR (5\%) with their average DCC.

[Insert Table 2 here]

${ }^{13}$ TDX (also called Tong Da Xin Financial Terminal) is software provided for analyzing the Chinese stock market All equity price data can be downloaded from TDX. To exclude the effect of dividend, we employ adjusted closing prices from TDX. 
We find that SPDB has the highest mean of $\triangle \mathrm{CoVaR}$ among the 16 banks, indicating the highest systemic risk contribution. The value of its $\triangle \mathrm{CoVaR}$ tells us that distress of SPDB (when its return is below $5 \% \mathrm{VaR}$ ) on average increases the $\mathrm{VaR}$ of the banking system by $166.9 \%$ compared to a normal situation for the SPDB.

Table 3 shows the ranking of banks according to their $\triangle \mathrm{CoVaR}$ for different periods. We separate the whole sample period into two periods (2007-2010 and 2011-2014), because the equity price data of $\mathrm{ABC}$ and $\mathrm{CEB}$ are only available since September 2010. Thus, the rankings for the first and second period are not completely comparable. The rankings of most of banks hardly change during 2007 to 2010 while they change dramatically between 2011 and 2014. This suggests that the banking system has undergone some changes since the global financial crisis (for example, see Cheung et al., 2016).

\section{[Insert Table 3 here]}

Furthermore, we consider the relation of $\triangle \mathrm{CoVaR}$ with bank size (measured by assets). We calculate Spearman rank's correlation between the banks' yearly average $\Delta \mathrm{CoVaR}$ and their assets and do the same for the different periods. The last row of Table 3 shows the results. The correlation between the ranking based on average $\triangle \mathrm{CoVaR}$ and that based on asset size drops from 0.57 in first period to 0.34 in the second period. The yearly correlation tends to decrease between 2009 and 2013, suggesting that bank size plays a smaller role in determining banks' systemic risk contribution during the post-crisis years, but it increases dramatically in 2014. Still, the coefficients are lower than 0.5 in most of years, indicating that the link between bank size and $\triangle \mathrm{CoVaR}$ is not very strong. For example, the coefficient is only 0.06 in 2013. This result reminds us that a relatively small bank can also exert a significant effect on the banking system's stability.

Finally, we divide the banks into three groups according to the classification of the China Banking Regulatory Commission and calculate their average $\Delta \mathrm{CoVaR}$. The Big-5 includes five large-scale commercial banks, the National-8 includes eight national joint-stock commercial banks and the City-3 includes three city joint-stock commercial banks. As shown in Table 4, we find that the Big-5's average $\Delta \mathrm{CoVaR}$ ranks first in both the first period (2007-2010) and in the second 
period (2011-2014). The mean values of $\Delta \mathrm{CoVaR}$ for the Big-5 and the National-8 decrease in the second period compared to the first period, whereas that of City-3 basically remains the same in the second period. As a result, the average $\Delta \mathrm{CoVaR}$ for City-3 ranks second in the second period. $\triangle \mathrm{CoVaR}$ is the highest in 2008 for all three groups and tends to decrease slowly in the following four years. However, the average $\Delta \mathrm{CoVaR}$ of the Big-5 tends to increase in 2013 and 2014, becoming almost as high as in 2008. In contrast, the average $\Delta \mathrm{CoVaR}$ of the National-8 and City-3 are lower, both compared to their own past levels and to the Big-5. Finally, we perform a t-test for equality of means of different groups' $\Delta \mathrm{CoVaR}$ and find that the differences of means among different groups are not always statistically significant. For example, there are no significant differences for the three groups in 2013, but in 2014, the Big-5's mean of $\Delta \mathrm{CoVaR}$ are significantly bigger than those of the National-8 and City-3. This reminds us that systemic risk of banks may be changing over time.

\section{[Insert Table 4 here]}

\subsection{Results for MES}

Table 5 shows the dynamic conditional correlations (DCC) between each bank and the banking system, the value at risk (VaR) at 5\% quantile of each bank, and the MES of each bank during the whole sample period. We find that NBCB has the highest mean of MES among the 16 banks. Equity returns of NBCB will drop on average by $1.02 \%$ when the banking system's return is below its $\mathrm{VaR}(5 \%)$. It should be noted that large banks, such as ICBC and $\mathrm{ABC}$, have a relatively small MES, which means that their marginal contributions to systemic risk are relatively low. In addition, we find that there is not a high cross-sectional correlation between MES and DCC (correlation coefficient is 0.106), or between VaR and DCC (correlation coefficient is -0.109 ). However, the correlation coefficient between MES and the absolute value of VaR is as high as 0.877. This suggests that banks with high VaR will suffer more from banking system distress.

[Insert Table 5 here]

To observe the change in the banks' rankings based on MES over time, Table 6 shows their 
rankings during different periods. The last row of Table 6 presents the Spearman rank correlation between MES and bank size, both on an annual basis and for different periods. It appears that most rankings hardly change over time. For example, NBCB ranks first in all years but 2008, when it came out second. The five large-scale banks rank last since 2010, suggesting their relatively strong ability to avoid losses in case of banking system distress. Spearman rank correlations between bank size and MES vary between -0.78 and -0.66 since 2009 , indicating a relatively high negative correlation between banks size and MES. In other words, a bigger bank tends to have a lower MES, contributing less to systemic risk of the banking system.

\section{[Insert Table 6 here]}

Table 7 shows the results for the three groups of banks according to the classification of the China Banking Regulatory Commission. It is clear that the MES of all three groups has decreased significantly in the second period compared to the first period. MES was the highest for all three groups in 2008; it decreased in the following four years, but rose again in 2013. In 2014, the MES of the three groups has declined to nearly half the average level of 2007-2010. The Big-5 banks have the smallest MES and the City-3 banks have the highest MES in all years except 2007. The t-tests show that the differences of the means among the different groups are statistically significant in all years except 2007. In other words, the City-3 banks have a significantly higher MES than the other two groups, which again reminds us to pay close attention to the systemic risk of small(er) banks.

\section{[Insert Table 7 here]}

\subsection{Results for SII}

We employ the SII approach to 14 listed banks ${ }^{14}$ in China for the full sample period. Table 8 reports the results. To understand our findings, let's take ICBC as an example. The estimated

\footnotetext{
${ }^{14}$ We exclude $\mathrm{ABC}$ and $\mathrm{CEB}$, because these two banks were only listed in 2010 so that there are not enough observations to calculate the SII and VII measures.
} 
systemic impact index of ICBC is almost 9, which suggests that almost 9 banks would fail if ICBC failed.

We find that the most and the least systemically important banks are not the biggest or the smallest banks, but are medium-sized banks. SPDB and CNCB, which rank in sixth and seventh places in terms of bank size, are the most and the least systemically important banks according to the SII measure, respectively. This suggests that bank size is not a key element for banks' systemic importance under this measure. Indeed, the Spearman rank correlation between bank size and SII is not significant (shown in the last row of Table 8).

There is little variation among results of banks' SII, and all banks' SII show a relatively high systemic impact. This may be explained by their high correlations with the banking system, where their correlations are all higher than 0.8 (see the last second column in Table 2). We expect that SII values would show more dispersion if we had more banks and their correlations with the banking system would have been lower (Zhou (2010) shows that SII values of 28 U.S. banks range from 6.53 to 12.44$)$.

[Insert $\underline{\text { Table } 8}$ here]

\subsection{Results for VI}

We apply the VI approach to 14 listed banks in China for the full sample period. Table 9 presents the rankings as well as the Spearman rank correlation between the VI and bank. To understand the results, let's take ICBC as an example. The value of the vulnerability index (VI) of ICBC is $35.8 \%$, indicating that the probability of ICBC being distressed would be $35.8 \%$ if at least one other bank becomes distressed.

We find that there is little variation of VI across different banks, and all VI values are higher than 33\% showing a relatively high vulnerability. Furthermore, the Spearman rank correlation between bank sizes and VI is not statistically significant, as shown in the last row of Table 9, suggesting that large banks are not the most systemically important banks.

[Insert Table 9 here] 


\subsection{Comparing rankings under the four systemic risk measures}

There is no criterion which can be derived from theoretical or empirical research for comparing our measures for systemic risk. In addition, the measures used capture different aspects of systemic risk. We therefore compare the rankings of the banks considered based on different measures (see Table 10), and compute the pairwise correlations among the rankings (see Table 11). The comparison focuses on 14 banks $^{15}$ for the full sample period (from 09-25-2007 to 12-31-2014).

Table 10 shows that there is no bank having the same rank under the four measures. For instance, ICBC ranks fifth according to the $\triangle \mathrm{CoVaR}$, while it ranks $13^{\text {th }}$, eighth and third according to the MES, the SII and the VI, respectively. Still, the pairwise correlations of the rankings based on the $\Delta \mathrm{CoVaR}$, the SII and the VI are all above 0.6 and are significant at least at the 5 percent level, but all of them only have very weak relations with the ranking based on the MES measure (see Table 11).

[Insert Table 10 and Table 11 here]

To examine developments over time, we show average $\triangle \mathrm{CoVaR}$ and average MES of all banks in Figure $5 .{ }^{16}$ In general, the movements of results of both measures are roughly aligned, indicating that systemic risk in the Chinese banking system tended to increase before the global financial crisis and reached a peak in October 2008. After the global financial crisis, systemic risk was relatively low. However, it began to rise in 2014, arriving at a relatively high level at the end of 2014.

[Insert Figure 5 here]

It is not surprising that different measures show similarities and differences as they have something in common but are not the same. Firstly, both $\Delta \mathrm{CoVaR}$ measure and SII are used to

\footnotetext{
${ }^{15}$ We cannot estimate the SII and the VI for these two banks due to the limited number of observations for ABC and $\mathrm{CEB}$, so the comparison of these four measures is based on 14 banks.

${ }^{16}$ Here we do not provide time series results of the SII and the VI because there are no time series results for these two measures.
} 
gauge the spillover effects from a bank to the banking system, while both MES and VI are used to capture banks' capacity to cope with negative shocks in the banking system. Secondly, both $\triangle \mathrm{CoVaR}$ and MES weigh the magnitude of a loss, whereas both SII and VI emphasize the probability of distress. We argue that these two reasons can partly explain the similarities and the differences among the results of the measures. In addition, they may be associated with some bank-specific factors, such as the dynamic correlation between returns of banks and the market, as shown by Benoit et al. (2013).

\subsection{Comparison with Korean banks}

In this section, we compare our results of $\triangle \mathrm{CoVaR}$ and MES for China with those for Korea presented by Yun and Moon (2014) ${ }^{17}$ The results shown in Table 12 for China and Korea refer to the same period, 2008-2013. We find that on average Chinese banks have a higher $\Delta \mathrm{CoVaR}$ than Korean banks. The mean $\Delta \mathrm{CoVaR}$ of China is nearly twice as high as that of Korea, which means that systemic risk of Chinese banks is much higher. In contrast, the mean MES of Chinese banks is lower than that of Korean banks, which suggests that the marginal systemic risk contribution of Chinese banks is lower than that of Korean banks. These findings suggest that $\triangle \mathrm{CoVaR}$ and MES, even though both are viewed as systemic risk measures, do capture different aspects of systemic risk, which is in line with our analyses in Section 4.5. We also find that the similarities and the differences of our measures of systemic risk are country-varying. For instance, the rankings based on $\triangle \mathrm{CoVaR}$ and MES have no significant correlation for Chinese banks while Yun and Moon (2014) find that they are highly correlated for Korean banks. Overall, our findings have the important policy implication that financial regulators should acknowledge the different meaning of different systemic risk measures, and that they should not rely on one single measure to identify systemic risk of banks.

[Insert Table 12 here]

\footnotetext{
${ }^{17}$ We also found some studies using these two measures as well as SII and VI for US banks, but they focus on the period before or during the 2008 financial crisis while our research focuses on the period of 2008-2014. Because financial markets in China have structurally changed during the financial crisis (see Cheung et al., 2016), meaningful comparisons of our results and those for US banks cannot be made.
} 


\section{Conclusions and discussions}

In this paper we review the development of Chinese banks since the 1990s and study their systemic risk since the recent global financial crisis by employing CoVaR, MES, SII and VI measures to listed Chinese banks. The CoVaR and the MES are calculated based on Engle's (2002) DCC model which allows for capturing time-varying nature of the systemic risk exposures of individual banks, a merit not shared by the quantile regression method also used to estimate the original CoVaR measure in Adrian and Brunnermeier (2016). The SII and the VI measures have been derived using the extreme value theory framework, which can overcome the problem of the scarcity of crisis observations.

We find that these four systemic risk measures yield different rankings for the banks considered, but correlations among rankings based on the $\Delta \mathrm{CoVaR}$, the SII and the VI measures are significant. We also find that these similarities and differences are time-varying. Despite the difference of $\triangle \mathrm{CoVaR}$ and MES with respect to the ranking of banks based on their systemic risk, they yield the same result that systemic risk in the Chinese banking system tended to increase during the global financial crisis and was relatively low after the crisis. However, systemic risk began to rise in 2014, arriving at a relatively high level at the end of 2014.

Finally, we compare our results of $\triangle \mathrm{CoVaR}$ and MES for Chinese banks with those for banks in Korea. It shows that Chinese banks have higher $\triangle \mathrm{CoVaR}$ but lower MES than Korean banks, implying that Chinese banks are systemic riskier and that they are more capable to avoid losses from banking system distress. An important policy implication is that financial regulators should acknowledge the different meaning of (changes in) $\triangle \mathrm{CoVaR}$, MES, SII and VI, and that they should not rely on one single measure.

A major challenge of market-based systemic risk measures is that their effectiveness depends on market efficiency. Although the Chinese stock market is imperfect, some recent studies find that it has become fairly efficient after the reform in 2005-2006 (see Wang et al., 2010; Patel et al., 2012; Chong et al., 2012) and stocks are priced rather rationally (Eun and Huang, 2007). The increased efficiency of stock markets in China supports the use of these market-based systemic risk measures, as also evidenced by their use in other studies (see, for instance, Gang and Qian, 2015).

Another concern is that some banks are partially owned by the government and therefore have a 
low free float rate, which may affect the representativeness of their stock prices in measuring banks' systemic risk. In our sample, the eight national joint-stock commercial banks and the three city joint-stock commercial banks are not owned by the government. Hence, our discussions focus on the five large-scale commercial banks (ICBC, $\mathrm{CCB}, \mathrm{ABC}, \mathrm{BOC}$ and $\mathrm{BCM}$ ), which are partially owned by the Chinese government (represented by the Ministry of Finance and Central Huijin Investment Co Ltd). The government holds about 70\%, 57\%, 79\%, 67\% and 26.5\% of stocks of ICBC, $\mathrm{CCB}, \mathrm{ABC}, \mathrm{BOC}$ and $\mathrm{BCM}$, respectively. And the government-owned proportions hardly changed during our sample period, even during the 2015 stock market crash. We believe that as long as the government does not frequently buy and sell banks' stocks with political purposes, banks' stock prices can still be informative. In addition, even excluding the proportions owned by the government, the rest of the negotiable market capitalizations (hereafter, adjusted Cap) of ICBC, $\mathrm{ABC}, \mathrm{BOC}$ and $\mathrm{BCM}$ are 360 billion, 196 billion, 239 billion and 164 billion Yuan, respectively. These four banks, in terms of their adjusted Cap, still rank in the Top 20 out of 2969 stocks in the Chinese stock market. ${ }^{18}$ Given their significant roles in the stock market, we have no reason to expect that these banks' stock prices would become less informative due to their ownership structure. Also previous studies (like Gang and Qian, 2015) used stock prices of Chinese banks to construct systemic risk measures.

All in all, we believe that these market-based systemic risk measures are informative and useful for China. We also advocate a thorough and systematic comparison of different measures of systemic risk in as many countries as possible. This would also make it possible to examine the similarities and differences amongst different systemic risk measures via panel models.

\footnotetext{
${ }^{18}$ For convenience and illustration, the market capitalizations are computed based on closing prices on October 25, 2016. We certify that the conclusion is the same when we look into historical information in our sample period.
} 


\section{References}

Acharya, V. V., L. H. Pedersen, T. Philippon and M. P. Richardson (2010) 'Measuring Systemic Risk', FRB of Cleveland Working Paper No. 10-02.

Adrian, T. and M. K. Brunnermeier (2016) 'CoVaR', American Economic Review 106, 1705-41.

Aizenman, J. (2015) 'Internationalization of the RMB, Capital Market Openness and Financial Reforms in China', Pacific Economic Review 20, 444-460.

Ariff, M. and C. Luc (2008) 'Cost and Profit Efficiency of Chinese Banks: A Non-parametric Analysis', China Economic Review 19, 260-273.

Asmild, M. and K. Matthews (2012) 'Multi-directional Efficiency Analysis of Efficiency Patterns in Chinese Banks 1997-2008', European Journal of Operational Research 219, 434-441.

Athanasoglou, P. P., S.N. Brissimis and M.D. Delis (2008) 'Bank-specific, Industry-specific and Macroeconomic Determinants of Bank Profitability', Journal of International Financial Markets, Institutions and Money 18, 121-136.

Bailey, W., W. Huang and Z. Yang (2012) 'Bank Loans with Chinese Characteristics: Some Evidence on Inside Debt in a State-Controlled Banking System', Journal of Financial and Quantitative Analysis 46, 1795-1830.

Benoit, S., G. Colletaz, C. Hurlin and C. Pérignon (2013) 'A Theoretical and Empirical Comparison of Systemic Risk Measures', HEC Paris Research Paper No. FIN-2014-1030.

Berger, A. N., I. Hasan and M. Zhou (2009) 'Bank Ownership and Efficiency in China: What will Happen in the World's Largest Nation?', Journal of Banking \& Finance 33, 113-130.

Bisias, D., M. Flood, A. W. Lo and S. Valavanis (2012) 'A Survey of Systemic Risk Analytics', Annual Review of Financial Economics 4, 255-296.

Blinder, A.S., M. Ehrmann, J. de Haan and D. Jansen (2016) 'Necessity as the Mother of Invention: Monetary Policy after the Crisis', NBER Working Paper No. 22735.

Brownlees, C. T. and R. F. Engle (2012) 'Volatility, Correlation and Tails for Systemic Risk Measurement', Available at SSRN: http://dx.doi.org/10.2139/ssrn.1611229.

Chen, Y., Y. Shi, X. Wei and L. Zhang (2014) 'Domestic Systemically Important Banks: A Quantitative Analysis for the Chinese Banking System', Mathematical Problems in Engineering 2014. 
Cheung, Y.W., S. Steinkamp and F. Westermann (2016) 'China's capital flight: Pre-and post-crisis experiences', Journal of International Money and Finance 66, 88-112.

Chong, T. T. L., T. H. Lam and I. K. M. Yan (2012) 'Is the Chinese Stock Market Really Inefficient?', China Economic Review 23, 122-137.

De Haan, L. and A. Ferreira (2007) 'Extreme Value Theory: An Introduction', Springer Science \& Business Media.

Dong, Y., M. Firth, W. Hou and W. Yang (2016) 'Evaluating the Performance of Chinese Commercial Banks: A Comparative Analysis of Different Types of Banks', European Journal of Operational Research 252, 280-295.

Engle, R. (2002) 'Dynamic Conditional Correlation: A Simple Class of Multivariate Generalized Autoregressive Conditional Heteroskedasticity Models', Journal of Business \& Economic Statistics 20, 339-350.

Eun, C.S. and W. Huang (2007) 'Asset pricing in China's domestic stock markets: Is there a logic?' Pacific-Basin Finance Journal, 15, 452-480.

Feldkircher, M. and I. Korhonen (2014) 'The Rise of China and Its Implications for the Global Economy: Evidence from a Global Vector Autoregressive Model', Pacific Economic Review 19, 61-89.

Fenech, J. P., Y. K. Yap and S. Shafik (2014) 'Can the Chinese Banking System Continue to Grow without Sacrificing Loan Quality?', Journal of International Financial Markets, Institutions and Money 31, 315-330.

Fu, X. M. and S. Heffernan (2009) 'The Effects of Reform on China's Bank Structure and Performance', Journal of Banking \& Finance 33, 39-52.

Gang, J. and Z. Qian (2015) 'China's Monetary Policy and Systemic Risk', Emerging Markets Finance \& Trade 51, 701-713.

García-Herrero, A., S. Gavila and D. Santabárbara (2006) 'China's Banking Reform: An Assessment of Its Evolution and Possible Impact', CESifo Economic Studies 52, 304-363.

García-Herrero, A. and D. Santabárbara (2004) 'Where is the Chinese Banking System Go ing with the Ongoing Reform?', EconWPA, Available at: http://EconPapers.repec.org/ RePEc:wpa:wuwpma:0408001.

Girardi, G. and A. Tolga Ergün (2013) 'Systemic Risk Measurement: Multivariate GARCH 
Estimation of CoVaR', Journal of Banking \& Finance 37, 3169-3180.

Hasan, I., N. Kobeissi, H. Wang and M. Zhou (2015) 'Banking Structure, Marketization, and Small Business Development: Regional Evidence from China', Pacific Economic Review, $20,487-510$

Huang, X., H. Zhou and H. Zhu (2012) 'Systemic Risk Contributions', Journal of Financial Services Research 42, 55-83.

Kim, K. S. and H. K. Chey (2010) 'Some Salient Issues Raised by the Global Financial Crisis', Pacific Economic Review 15, 1-10.

Koetter, M. and T. Poghosyan (2010) 'Real Estate Prices and Bank Stability', Journal of Banking \& Finance 34, 1129-1138.

Krugman, P. (2011) ‘Will China Break?’, The New York Times 18.

Li, T. (2014) 'Shadow Banking in China: Expanding Scale, Evolving Structure', Journal of Financial Economic Policy 6, 198-211.

Lin, X. and Y. Zhang (2009) 'Bank Ownership Reform and Bank Performance in China', Journal of Banking \& Finance 33, 20-29.

Lo, A. W. (2008) 'Hedge Funds, Systemic Risk, and the Financial Crisis of 2007-2008: Written Testimony for the House Oversight Committee Hearing on Hedge Funds', Available at SSRN: http://dx.doi.org/10.2139/ssrn.1301217.

Mainik, G. and E. Schaanning (2014) 'On Dependence Consistency of CoVar and Some Other Systemic Risk Measures', Statistics \& Risk Modeling 31, 49-77.

Patel, N. R., N. Radadia and J. Dhawan (2012) 'An Empirical Study on Weak-Form of Market Efficiency of Selected Asian Stock Markets', Journal of Applied Finance \& Banking 2, $98-148$

Pasiouras, F. and K. Kosmidou (2007) 'Factors Influencing the Profitability of Domestic and Foreign Commercial Banks in the European Union', Research in International Business and Finance 21, 222-237.

Podpiera, R. (2006) 'Progress in China's Banking Sector Reform: Has Bank Behavior Changed?', IMF Working Paper No. 06/71.

Qiu, L. D. and C. Zhan (2016) 'China's Global Influence: A Survey through the Lens of International Trade', Pacific Economic Review 21, 45-71. 
Segoviano, M. and C. Goodhart (2009) 'Bank Stability Measures', IMF Working Paper 09/4.

Van Oordt, M. R. And C. Zhou (2012) ‘The Simple Econometrics of Tail Dependence', Economics Letters 116, 371-373.

Wang, Y., L. Liu, R. Gu, J. Cao and H. Wang (2010) 'Analysis of Market Efficiency for the Shanghai Stock Market over Time', Physica A: Statistical Mechanics and its Applications $389,1635-1642$.

Wang, Y., X. Shan and J. Geng (2015) 'Estimating the Systemic Risk of China's Banking Industries Based on Merton Model', Applied Mathematics \& Information Sciences 9, 957-964.

Yun, J. and H. Moon (2014) 'Measuring Systemic Risk in the Korean Banking Sector via Dynamic Conditional Correlation Models', Pacific-Basin Finance Journal 27, 94-114.

Zhou, C. (2010) 'Are banks too big to fail?', Measuring Systemic Importance of Financial Institutions', International Journal of Central Banking 6, 205-250. 


\section{Figures}

Figure 1. Assets and liabilities of the Chinese banking system

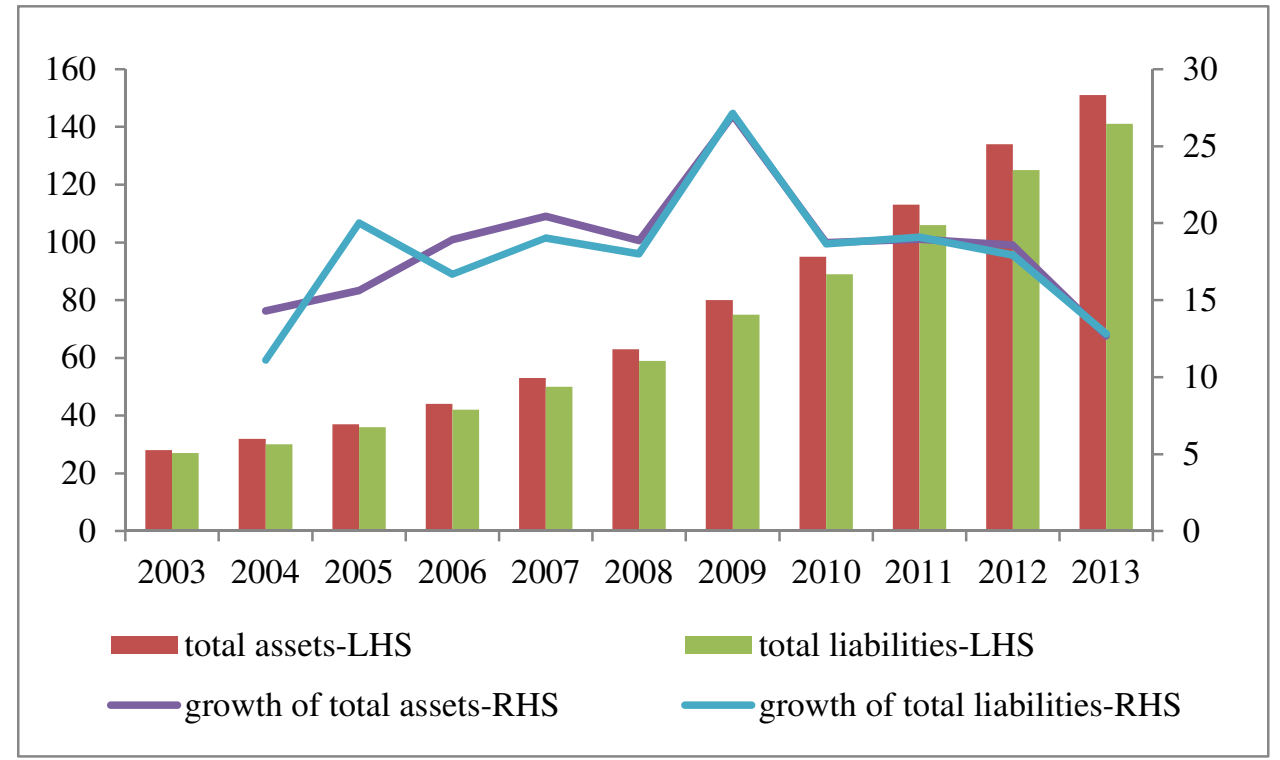

Note: The unit of the assets and liabilities is trillion Yuan. The unit of the growth rate is percent. Source: China Banking Regulatory Commission Annual Report 2013; and authors' calculation.

Figure 2. Profits of the Chinese banking system

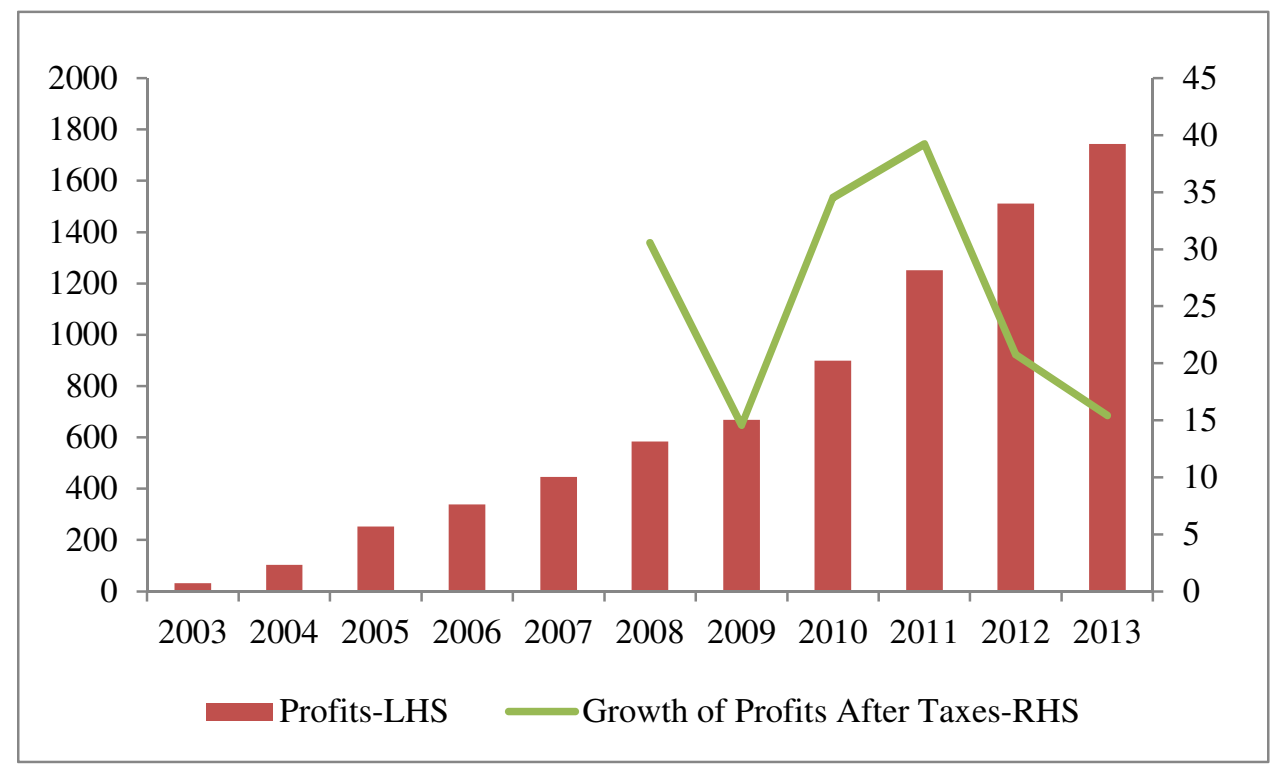

Note: The unit of the profits is million Yuan. The unit of the growth rate is percent. Profits before taxes are shown for 2003- 2006 and after taxes for 2007- 2013 due to a change in statistical standard. Source: China Banking Regulatory Commission Annual Report 2013; and authors' calculation. 
Figure 3. Distribution of Banking Assets in 2013

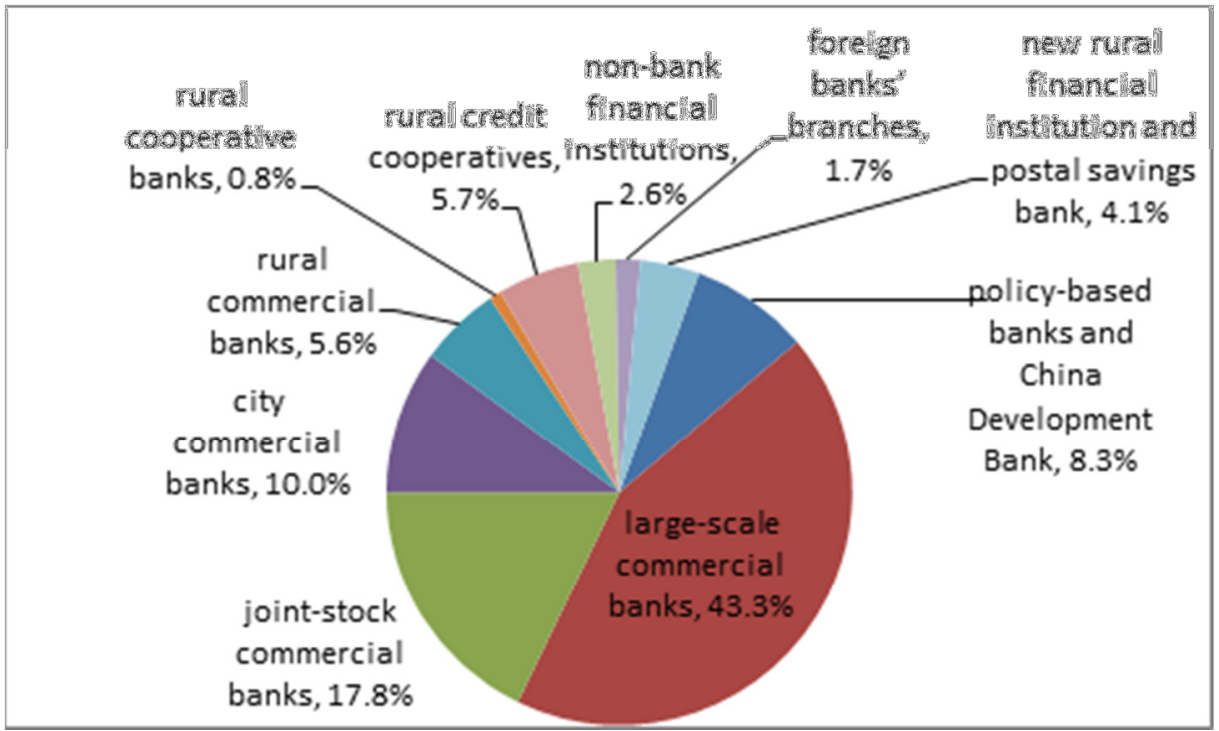

Source: China Banking Regulatory Commission Annual Report 2013; and authors' calculation.

Figure 4. Distribution of Banking Profits after Taxes in 2013

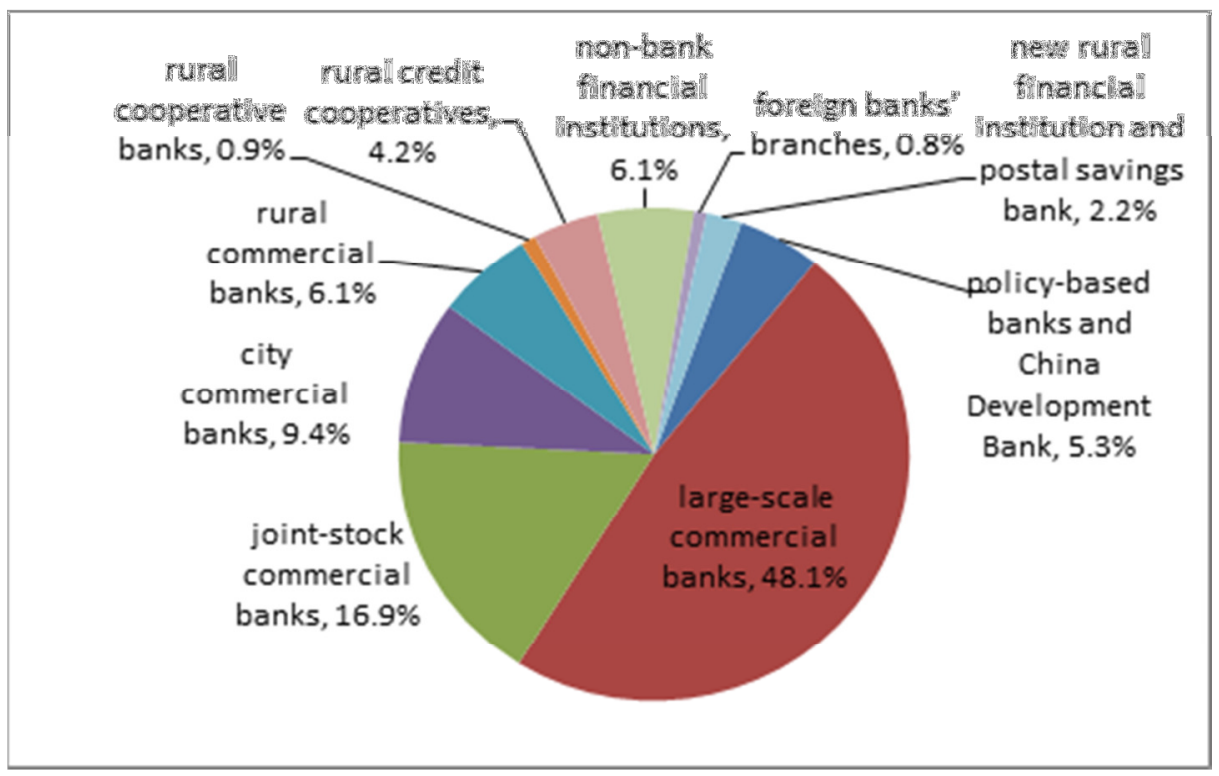

Source: China Banking Regulatory Commission Annual Report 2013; Authors' calculation. 


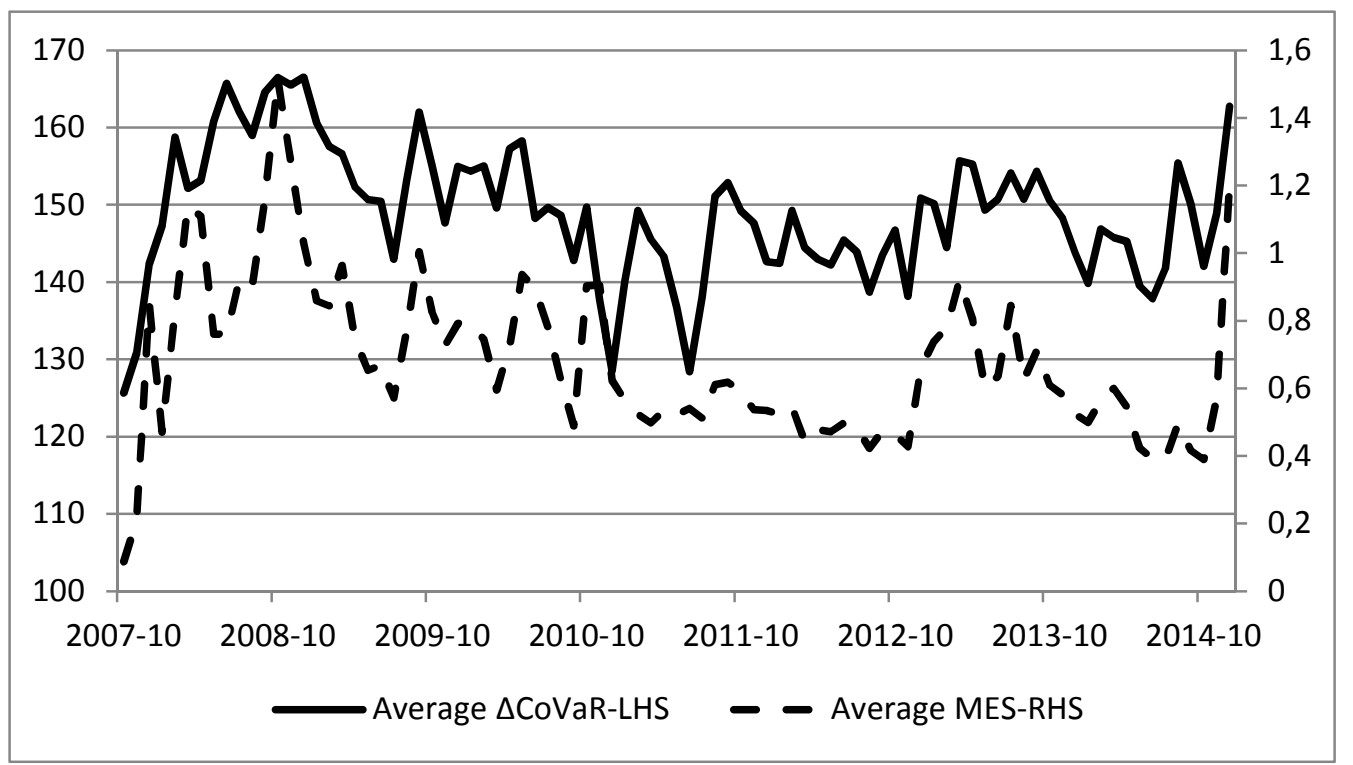

Figure 5. Average $\triangle \mathrm{CoVaR}$ and Average MES of all sample banks

Note: The units of the average $\triangle \mathrm{CoVaR}$ and the average MES are percent. Source: authors' calculation. 


\section{Tables}

Table 1. Descriptive statistics of daily log-returns of 16 Chinese banks 9/25/2007- 12/31/2014

\begin{tabular}{c|ccccccc}
\hline Banks & Mean $(\%)$ & Std. $(\%)$ & Max $(\%)$ & Min $(\%)$ & Skew. & Kurt. & Obs. \\
\hline ICBC & -0.001 & 0.021 & 0.139 & -0.156 & 0.08 & 11.40 & 1765 \\
CCB & 0.000 & 0.022 & 0.139 & -0.152 & 0.06 & 9.87 & 1765 \\
ABC & 0.051 & 0.014 & 0.104 & -0.097 & 0.83 & 12.40 & 1050 \\
BOC & -0.005 & 0.019 & 0.127 & -0.125 & 0.44 & 10.82 & 1765 \\
BCM & -0.018 & 0.023 & 0.108 & -0.115 & 0.10 & 7.13 & 1765 \\
CMB & -0.015 & 0.023 & 0.097 & -0.105 & 0.02 & 6.27 & 1765 \\
SPDB & 0.005 & 0.031 & 0.154 & -0.157 & 0.04 & 7.34 & 1765 \\
CNCB & -0.004 & 0.025 & 0.104 & -0.111 & 0.18 & 6.20 & 1765 \\
CIB & 0.002 & 0.028 & 0.107 & -0.116 & -0.03 & 5.56 & 1765 \\
CMBC & 0.023 & 0.027 & 0.130 & -0.140 & 0.06 & 6.85 & 1765 \\
CEB & 0.017 & 0.019 & 0.107 & -0.098 & 0.75 & 9.01 & 1050 \\
HB & -0.002 & 0.030 & 0.127 & -0.137 & -0.10 & 6.33 & 1765 \\
PAB & 0.004 & 0.029 & 0.102 & -0.112 & 0.10 & 5.46 & 1765 \\
BOB & -0.012 & 0.026 & 0.120 & -0.132 & -0.08 & 6.64 & 1765 \\
NBCB & -0.016 & 0.028 & 0.120 & -0.130 & -0.04 & 6.24 & 1765 \\
BON & 0.012 & 0.023 & 0.106 & -0.107 & 0.17 & 5.96 & 1765 \\
Sector & -0.004 & 0.019 & 0.096 & -0.104 & -0.01 & 7.77 & 1765 \\
\hline
\end{tabular}

Notes: Sector is Banking Sector Index. ICBC: Industrial and Commercial Bank of China; CCB: China Construction Bank; ABC: Agricultural Bank of China; BOC: Bank of China; BCM: Bank of Communications; CMB: China Merchants Bank Co., Ltd; CNCB: China CITIC Bank; CIB: Industrial Bank Co., Ltd; SPDB: Shanghai Pudong Development Bank; CMBC: China Minsheng Banking Co., Ltd; CEB: China Everbright Bank; PAB: Ping An Bank; HB: Huaxia Bank; BOB: Bank of Beijing; BON: Bank of Nanjing; NBCB: Bank of Ningbo. Sample period is from 9/26/2007 to 12/31/2014 for all banks except for ABC and CEB, for which the sample period is from 9/1/2010 to 12/31/2014. Banks listed in the first column are sorted in descending order of their average assets during the sample period. Source: authors' calculations using data provided by TDX. 
Table 2. Descriptive statistics of $\triangle \mathrm{CoVaR}, \mathrm{DCC}$ and VaR $(5 \%)$

\begin{tabular}{c|cccccc}
\hline Banks & Mean $(\boldsymbol{\%})$ & Std. $(\boldsymbol{\%})$ & Max $(\boldsymbol{\%})$ & Min $(\boldsymbol{\%})$ & DCC Ave. & VaR (5\%) Ave. $(\%)$ \\
\hline ICBC & 156.59 & 11.68 & 193.71 & 88.14 & 0.88 & -3.05 \\
CCB & 147.53 & 18.18 & 191.67 & 68.66 & 0.86 & -3.21 \\
ABC & 138.32 & 18.34 & 187.67 & 78.45 & 0.83 & -2.12 \\
BOC & 148.90 & 11.07 & 194.94 & 106.35 & 0.86 & -2.82 \\
BCM & 157.32 & 7.07 & 198.30 & 64.00 & 0.89 & -3.50 \\
CMB & 164.87 & 15.75 & 194.98 & 112.67 & 0.90 & -3.55 \\
SPDB & 166.85 & 13.40 & 196.86 & 120.18 & 0.91 & -4.64 \\
CNCB & 139.28 & 18.45 & 176.34 & 75.21 & 0.83 & -3.89 \\
CIB & 160.42 & 10.43 & 184.55 & 120.35 & 0.89 & -4.41 \\
CMBC & 152.59 & 20.32 & 194.97 & 78.01 & 0.87 & -4.17 \\
CEB & 136.41 & 20.22 & 203.72 & 24.44 & 0.82 & -2.83 \\
HB & 142.95 & 17.41 & 182.63 & 50.25 & 0.84 & -4.58 \\
PAB & 136.51 & 26.54 & 193.72 & 17.54 & 0.81 & -4.42 \\
BOB & 143.95 & 13.94 & 166.67 & 52.86 & 0.85 & -3.93 \\
NBCB & 132.36 & 13.69 & 161.54 & 69.57 & 0.81 & -4.30 \\
BON & 143.83 & 15.92 & 183.03 & 66.85 & 0.85 & -3.71 \\
\hline
\end{tabular}

Notes: see Table 1 for abbreviations for the banks. Sample period is from 9/26/2007 to 12/31/2014 for all banks except for ABC and CEB, whose sample period is from 9/1/2010 to 12/31/2014. Banks listed in the first column are sorted in descending order of their average assets during the sample period.

Table 3. Ranking of banks based on yearly average $\triangle \mathrm{CoVaR}$ of each bank

\begin{tabular}{c|cccccccccc}
\hline$\Delta$ CoVaR & $\mathbf{2 0 0 7 - 1 0}$ & $\mathbf{2 0 1 1 - 1 4}$ & $\mathbf{2 0 0 7}$ & $\mathbf{2 0 0 8}$ & $\mathbf{2 0 0 9}$ & $\mathbf{2 0 1 0}$ & $\mathbf{2 0 1 1}$ & $\mathbf{2 0 1 2}$ & $\mathbf{2 0 1 3}$ & $\mathbf{2 0 1 4}$ \\
\hline ICBC & 5 & 5 & 5 & 8 & 4 & 4 & 5 & 3 & 9 & 5 \\
CCB & 7 & 11 & 9 & 6 & 5 & 7 & 9 & 13 & 14 & 8 \\
ABC & -- & 12 & -- & -- & -- & -- & 13 & 16 & 11 & 6 \\
BOC & 8 & 6 & 8 & 12 & 8 & 9 & 6 & 11 & 7 & 7 \\
BCM & 6 & 3 & 4 & 7 & 7 & 5 & 2 & 4 & 3 & 4 \\
CMB & 1 & 4 & 1 & 1 & 1 & 1 & 3 & 1 & 12 & 3 \\
SPDB & 2 & 1 & 3 & 2 & 2 & 3 & 1 & 2 & 1 & 1 \\
CNCB & 9 & 14 & 10 & 9 & 12 & 10 & 15 & 8 & 8 & 16 \\
CIB & 4 & 2 & 2 & 4 & 3 & 6 & 4 & 5 & 2 & 2 \\
CMBC & 3 & 10 & 6 & 3 & 6 & 2 & 11 & 10 & 4 & 11 \\
CEB & -- & 13 & -- & -- & -- & -- & 16 & 12 & 13 & 12 \\
HB & 12 & 8 & 12 & 10 & 9 & 12 & 10 & 7 & 6 & 9 \\
PAB & 13 & 15 & 7 & 5 & 14 & 14 & 14 & 14 & 16 & 10 \\
BOB & 11 & 7 & 14 & 13 & 10 & 8 & 7 & 6 & 10 & 13 \\
NBCB & 14 & 16 & 13 & 14 & 13 & 13 & 12 & 15 & 15 & 15 \\
BON & 10 & 9 & 11 & 11 & 11 & 11 & 8 & 9 & 5 & 14 \\
Spearman Correlation & 0.57 & 0.34 & 0.47 & 0.37 & 0.58 & 0.46 & 0.32 & 0.14 & 0.06 & 0.58 \\
\hline
\end{tabular}

Notes: see Table 1 for abbreviations for the banks. Sample period is from 9/26/2007 to 12/31/2014 for all banks except for ABC and CEB, whose sample period is from 9/1/2010 to 12/31/2014. Banks listed in the first column are sorted in descending order of their average assets during the sample period. The last row shows the Spearman correlation between banks' sizes and systemic importance. 
Table 4. Yearly average $\Delta \mathrm{CoVaR}$ of different banks groups (\%)

\begin{tabular}{l|rrrrrrrrrr}
\hline Groups & $\mathbf{2 0 0 7 - 2 0 1 0}$ & $\mathbf{2 0 1 1 - 2 0 1 4}$ & $\mathbf{2 0 0 7}$ & $\mathbf{2 0 0 8}$ & $\mathbf{2 0 0 9}$ & $\mathbf{2 0 1 0}$ & $\mathbf{2 0 1 1}$ & $\mathbf{2 0 1 2}$ & $\mathbf{2 0 1 3}$ & $\mathbf{2 0 1 4}$ \\
\hline Big-5 & 155.1 & 148.4 & 145.5 & 157.2 & 156.1 & 147.3 & 146.7 & 142.8 & 150.7 & 153.3 \\
National-8 & 154.4 & 144.3 & 141.3 & 166.4 & 153.3 & 142.3 & 139.4 & 144.7 & 149.7 & 143.7 \\
City-3 & 146.9 & 146.6 & 106.2 & 153.6 & 150.9 & 146.6 & 147.0 & 144.3 & 152.5 & 143.0 \\
\hline
\end{tabular}

Notes: Big-5 includes ICBC, CCB, ABC, BOC and BCM; National-8 includes CMB, SPDB, CNCB, CIB, CMBC, CEB, HB and PAB; City-3 includes BOB, NBCB and BON.

Table 5. Descriptive statistics of MES, DCC and VaR (5\%)

\begin{tabular}{c|cccccc}
\hline Banks & Mean $(\boldsymbol{\%})$ & Std. $(\boldsymbol{\%})$ & Max $(\boldsymbol{\%})$ & Min $(\boldsymbol{\%})$ & DCC Ave. & VaR (5\%) Ave. $(\boldsymbol{\%})$ \\
\hline ICBC & 0.56 & 0.34 & 2.84 & 0.20 & 0.88 & -3.05 \\
CCB & 0.63 & 0.38 & 2.95 & 0.23 & 0.86 & -3.21 \\
ABC & 0.32 & 0.11 & 1.14 & 0.15 & 0.83 & -2.12 \\
BOC & 0.56 & 0.31 & 2.20 & 0.20 & 0.86 & -2.82 \\
BCM & 0.60 & 0.28 & 2.10 & 0.26 & 0.89 & -3.50 \\
CMB & 0.72 & 0.31 & 1.86 & 0.32 & 0.90 & -3.55 \\
SPDB & 0.83 & 0.46 & 2.78 & 0.29 & 0.91 & -4.64 \\
CNCB & 0.68 & 0.23 & 1.84 & 0.35 & 0.83 & -3.89 \\
CIB & 0.85 & 0.33 & 2.07 & 0.39 & 0.89 & -4.41 \\
CMBC & 0.84 & 0.40 & 2.56 & 0.31 & 0.87 & -4.17 \\
CEB & 0.35 & 0.16 & 1.23 & 0.18 & 0.82 & -2.83 \\
HB & 0.92 & 0.39 & 2.40 & 0.40 & 0.84 & -4.58 \\
PAB & 0.71 & 0.31 & 1.76 & 0.09 & 0.81 & -4.42 \\
BOB & 0.92 & 0.38 & 2.66 & 0.43 & 0.85 & -3.93 \\
NBCB & 1.02 & 0.38 & 2.65 & 0.46 & 0.81 & -4.30 \\
BON & 0.76 & 0.27 & 1.77 & 0.33 & 0.85 & -3.71 \\
\hline
\end{tabular}

Notes: see Table 1 for abbreviations for the banks. Sample period is from 9/26/2007 to 12/31/2014 for all banks except for ABC and CEB, whose sample period is from $9 / 1 / 2010$ to $12 / 31 / 2014$. Banks listed in the first column are sorted in descending order of their average assets during the sample period. 
Table 6. Ranking of banks based on yearly average of MES

\begin{tabular}{c|cccccccccc}
\hline Banks & $2007-10$ & $2011-$ & 2007 & 2008 & 2009 & 2010 & 2011 & 2012 & 2013 & 2014 \\
\hline ICBC & 11 & 14 & 2 & 11 & 14 & 13 & 13 & 13 & 15 & 14 \\
CCB & 10 & 12 & 8 & 9 & 9 & 12 & 11 & 12 & 12 & 13 \\
ABC & -- & 16 & -- & -- & -- & -- & 16 & 15 & 16 & 16 \\
BOC & 14 & 13 & 5 & 12 & 11 & 14 & 14 & 14 & 13 & 12 \\
BCM & 13 & 11 & 12 & 13 & 12 & 11 & 12 & 11 & 11 & 11 \\
CMB & 7 & 10 & 9 & 7 & 7 & 9 & 8 & 9 & 10 & 10 \\
SPDB & 4 & 8 & 6 & 1 & 5 & 7 & 7 & 8 & 7 & 9 \\
CNCB & 12 & 7 & 14 & 14 & 13 & 6 & 9 & 7 & 9 & 3 \\
CIB & 6 & 4 & 3 & 6 & 6 & 4 & 4 & 5 & 2 & 6 \\
CMBC & 5 & 5 & 4 & 5 & 4 & 8 & 6 & 6 & 3 & 5 \\
CEB & -- & 15 & -- & -- & -- & -- & 15 & 16 & 14 & 15 \\
HB & 3 & 3 & 7 & 3 & 2 & 3 & 2 & 2 & 5 & 4 \\
PAB & 9 & 9 & 10 & 8 & 10 & 10 & 10 & 10 & 6 & 8 \\
BOB & 2 & 2 & 11 & 4 & 3 & 2 & 3 & 3 & 4 & 2 \\
NBCB & 1 & 1 & 1 & 2 & 1 & 1 & 1 & 1 & 1 & 1 \\
BON & 8 & 6 & 13 & 10 & 8 & 5 & 5 & 4 & 8 & 7 \\
Spearman & $-0.68 * *$ & $-0.75 * *$ & 0.09 & -0.46 & $-0.66 * *$ & $-0.78^{* *}$ & $-0.73 * *$ & $-0.71 * *$ & $-0.69 * *$ & $-0.71 * *$ \\
Correlation & & & & & & & & & & 5 \\
\hline
\end{tabular}

Notes: see Table 1 for abbreviations for the banks. Sample period is from 9/26/2007 to 12/31/2014 for all banks except for ABC and CEB, whose sample period is from 9/1/2010 to 12/31/2014. Banks listed in the first column are sorted in descending order of their average assets during the sample period. **. Correlation is significant at the 0.01 level. The last row shows the Spearman correlation between banks' sizes and systemic importance.

Table 7. Yearly average MES of different banks groups (\%)

\begin{tabular}{c|cccccccccc}
\hline Groups & $2007-2010$ & $2011-2014$ & 2007 & 2008 & 2009 & 2010 & 2011 & 2012 & 2013 & 2014 \\
\hline Big-5 & 0.81 & 0.39 & 0.95 & 1.09 & 0.76 & 0.54 & 0.39 & 0.33 & 0.41 & 0.42 \\
National-8 & 0.99 & 0.57 & 0.9 & 1.35 & 0.93 & 0.72 & 0.55 & 0.47 & 0.73 & 0.55 \\
City-3 & 1.13 & 0.68 & 0.92 & 1.54 & 1.04 & 0.86 & 0.68 & 0.61 & 0.81 & 0.62 \\
\hline
\end{tabular}

Notes: Big-5 includes ICBC, CCB, ABC, BOC and BCM; National-8 includes CMB, SPDB, CNCB, CIB, CMBC, CEB, HB and PAB; City-3 includes BOB, NBCB and BON. 
Table 8. Results for SII

\begin{tabular}{c|c|c}
\hline Banks & SII & Systemic Importance Ranking \\
\hline ICBC & 8.9789 & 8 \\
CCB & 9.0737 & 5 \\
BOC & 8.6316 & 12 \\
BCM & 9.3263 & 3 \\
CMB & 9.4105 & 2 \\
SPDB & 9.4842 & 1 \\
CNCB & 8.5684 & 14 \\
CIB & 9.2211 & 4 \\
CMBC & 8.9895 & 7 \\
HB & 8.9053 & 9 \\
PAB & 8.6526 & 11 \\
BOB & 9.0421 & 6 \\
NBCB & 8.6105 & 13 \\
BON & 8.6842 & 10 \\
\hline \multicolumn{2}{c}{ Spearman Correlation } \\
\hline
\end{tabular}

Notes: SII is the systemic importance index, defined as the number of expected banks failures given a particular bank fails. See Table 1 for abbreviations for the banks. Sample period is from 9/26/2007 to 12/31/2014 for all banks. Banks listed in the first column are sorted in descending order of their average assets during the sample period. The last row shows the Spearman correlation between banks' sizes and systemic importance.

Table 9. Results for VI

\begin{tabular}{c|c|c}
\hline Banks & VI (\%) & Systemic Importance Ranking \\
\hline ICBC & 35.80 & 3 \\
CCB & 35.04 & 8 \\
BOC & 33.73 & 12 \\
BCM & 36.05 & 2 \\
CMB & 36.29 & 1 \\
SPDB & 35.55 & 5 \\
CNCB & 33.73 & 12 \\
CIB & 35.55 & 5 \\
CMBC & 34.52 & 11 \\
HB & 35.80 & 3 \\
PAB & 33.20 & 14 \\
BOB & 35.29 & 7 \\
NBCB & 35.04 & 8 \\
BON & 35.04 & 8 \\
\hline \multicolumn{2}{l}{ Spearman Correlation }
\end{tabular}

Notes: VI is the vulnerability index, defined as the probability of failure given there exists at least another bank failure in the system. See Table 1 for abbreviations for the banks. Sample period is from 9/26/2007 to 12/31/2014 for all banks. Banks listed in the first column are sorted in descending order of their average assets during the sample period. The last row shows the Spearman correlation between banks' sizes and systemic importance. 
Table 10. Systemically important banks' rankings in the full sample period

\begin{tabular}{c|cccc}
\hline Banks & $\Delta$ CoVaR & MES & SII & VI \\
\hline ICBC & 5 & 13 & 8 & 3 \\
CCB & 8 & 11 & 5 & 8 \\
BOC & 7 & 13 & 12 & 12 \\
BCM & 4 & 12 & 3 & 2 \\
CMB & 2 & 8 & 2 & 1 \\
SPDB & 1 & 6 & 1 & 5 \\
CNCB & 12 & 10 & 14 & 12 \\
CIB & 3 & 4 & 4 & 5 \\
CMBC & 6 & 5 & 7 & 11 \\
HB & 11 & 2 & 9 & 3 \\
PAB & 13 & 9 & 11 & 14 \\
BOB & 9 & 2 & 6 & 7 \\
NBCB & 14 & 1 & 13 & 8 \\
BON & 10 & 7 & 10 & 8 \\
\hline
\end{tabular}

Table 11. Pearson correlations among rankings of systemically important banks

\begin{tabular}{c|cccc}
\hline & $\Delta$ CoVaR & MES & SII & VI \\
\hline$\Delta$ CoVaR & 1.00 & & & \\
MES & -0.24 & 1.00 & & \\
SII & $0.85 * *$ & 0.03 & 1.00 & \\
VI & $0.61 *$ & 0.08 & $0.70 * *$ & 1.00 \\
\hline
\end{tabular}

Notes: **. Correlation is significant at the 0.01 level. *. Correlation is significant at the 0.05 level.

Table 12. Systemic risk in China and Korea: $\triangle \mathrm{CoVaR}$ and MES

\begin{tabular}{l|rrrr}
\hline \multicolumn{1}{c|}{ Results } & Mean (\%) & Std. (\%) & Max (\%) & Min (\%) \\
\hline$\Delta$ CoVaR in this paper & 148.4 & 11.1 & 168.1 & 131.6 \\
$\Delta$ CoVaR in Yun and Moon (2014) & 79.9 & 21.4 & 106.8 & 33.4 \\
MES in this paper & 0.72 & 0.21 & 1.06 & 0.32 \\
MES in Yun and Moon (2014) & 2.84 & 0.9 & 3.8 & 0.7 \\
\hline
\end{tabular}

Notes: $\triangle$ CoVaR (MES) in Yun and Moon (2014) are the mean $\triangle$ CoVaR (MES) of ten banks in Korea during 2008-2013. $\triangle \mathrm{CoVaR}$ (MES) in this paper reported here are the mean $\triangle \mathrm{CoVaR}$ (MES) of 16 banks in China during 2008-2013. 